\title{
VARIABILIDADE MORFOLÓGICA EM NÍVEIS DE BASE DO RIO MARACUJÁ (QUADRILÁTERO FERRÍFERO - MG): INFLUÊNCIAS LITOLÓGICAS, ESTRUTURAIS E DE REATIVAÇÕES CENOZÓICAS
}

\author{
Claudio Eduardo Lana \\ Universidade Federal do Espirito Santo - Centro de Ciências Agrárias - Departamento de Engenharia Rural - \\ Alto Universitário, s/n-Alegre - ES - e-mail: claudiolana@cca.ufes.br \\ Paulo de Tarso Amorim Castro \\ Universidade Federal de Ouro Preto - Departamento de Geologia - Campus Morro do Cruzeiro - \\ Ouro Preto - MG - e-mail: paulo_de_tarso@degeo.ufop.br
}

\begin{abstract}
Resumo
Este trabalho apresenta os resultados de um estudo sobre a evolução morfológica e sedimentar de três níveis de base ao longo do rio Maracujá, afluente do rio das Velhas. Os segmentos estudados drenam rochas metaígneas e metassedimentares da porção sul do Quadrilátero Ferrífero. A identificação dos níveis de base se deu a partir da análise de modelos tridimensionais de declividade, gerados sobre uma imagem de radar SRTM. Posteriormente procedeu-se o mapeamento dos pontos na escala de 1:500, com o uso de Estação Total. Foram também descritos perfis de fácies sedimentares que, juntamente com os dados morfológicos e geológicos, levaram a interpretações sobre o processo evolutivo dos segmentos estudados, bem como dos condicionantes desta evolução.
\end{abstract}

Palavras-chave: níveis de base, sistema fluvial, geomorfologia tectônica.

\begin{abstract}
This work deals with the morphological and sedimentological evolution of 3 Maracujá river base levels. This river is a Velhas river affluent. It is draining metaigneous and metasedimentary rocks of the southern portion of Quadrilátero Ferrífero. The investigated fluvial segments were identified from analysis of tridimensional slope models, generated from a SRTM radar image. After that, these points were surveyed with a Total Station at 1:500 scale. In addition, stratigraphic logs were described. Geologic maps were studied in order to provide interpretations of the segments' evolutive processes, as well as their determining factors.
\end{abstract}

Keywords: base levels, fluvial system, tectonic geomorphology.

\section{Introdução}

O rio das Velhas é o principal afluente da margem direita do rio São Francisco. Sua bacia drena terrenos de geologia muito heterogênea, resultando em um notável quadro morfológico e ambiental.
No alto curso, a bacia está instalada sobre rochas do Quadrilátero Ferrífero, uma região estudada sob diferentes enfoques, devido ao contexto litoestrutural, geomorfológico e ambiental reconhecidamente diverso e complexo. 
Uma grande geodiversidade é normalmente traduzida na alta variabilidade morfológica e sedimentar dos cursos d'água. De acordo com Schumm (1977), os rios sofrem alterações no seu perfil longitudinal de equilíbrio ao se depararem com alterações significativas das propriedades geológicas e/ou de uso antrópico do canal e suas faixas marginais.

Em linhas gerais, os rios se tornam escalonados e os patamares gerados são denominados níveis de base ou, mais apropriadamente, níveis de base geomórficos (Shanley \& McCabe, 1994). Nessas áreas prevalecem os processos sedimentares de deposição. Entretanto, as formas geradas podem variar no tempo e no espaço, em função de uma grande gama de variáveis.

Como exemplos de fatores que influenciam a geração e conformação dos níveis de base, podem-se considerar: alterações eustáticas (Catuneanu, 2007), reajustes isostáticos (Holbrook \& Schumm, 1999), basculamentos tectônicos (Leeder \& Gawthorpe, 1987), justaposição litológica (Tooth et al., 2004), constituição sedimentar dos leitos (Turner \& Locke, 2005), intervenções antrópicas (Nelson, 1998), entre outros.

As diferentes fases evolutivas pelas quais passa o curso d'água podem, segundo Miall (2006), ser registradas nas fácies presentes em pacotes sedimentares de seus terraços e/ ou planície de inundação.

O rio Maracujá é afluente do alto curso do rio das Velhas e, a partir de suas cabeceiras, drena rochas metassedimentares, passando a terrenos granito-gnáissicos bastante fraturados, conduzindo à instalação de níveis de base a partir de condicionantes distintos. Além disso, o mesmo apresenta variados graus de intervenções antrópicas associadas à urbanização e ao garimpo de topázio.

Os fatos expostos demonstram a importância de se compreenderem os processos e produtos locais da instalação das zonas de retenção de sedimentos ao longo da bacia em apreço,

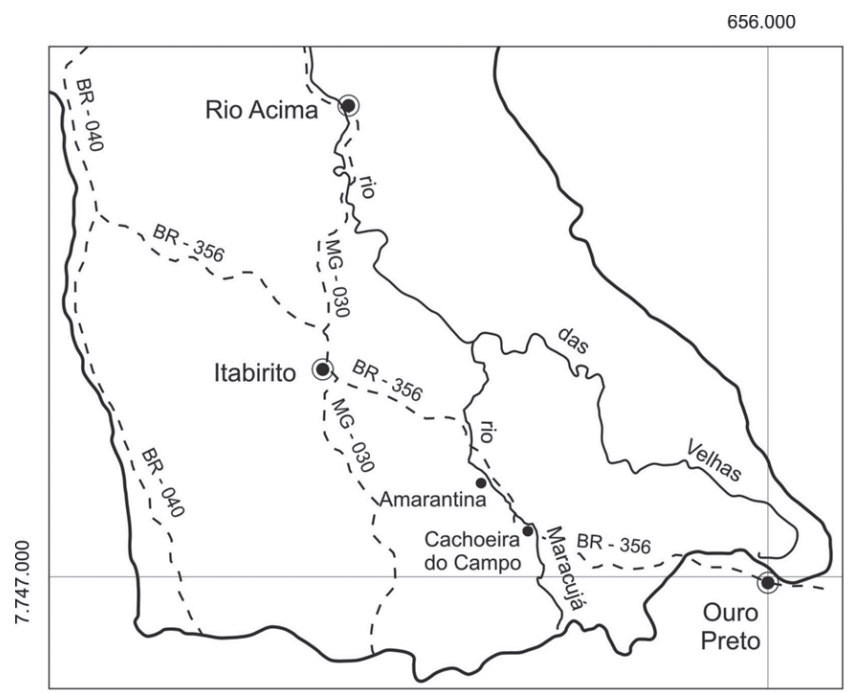

utilizando não só recursos geomorfológicos, mas também métodos estratigráficos e sedimentológicos de investigação.

Este trabalho teve como objetivos:

- identificar os níveis de base geomórficos ao longo do canal principal do rio Maracujá;

- em cada um deles, mapear em escala de detalhe (1:500) um segmento fluvial acessível;

- identificar pacotes sedimentares nos segmentos mapeados e descrever suas fácies sedimentares;

- analisar o contexto geológico regional de cada um dos níveis de base estudados e revisar a literatura pertinente às zonas de deformação cenozóica com provável influência sobre os segmentos mapeados;

- confrontar os perfis estratigráficos e os mapas geomorfológicos com a geologia de cada segmento;

- efetuar uma comparação dos processos evolutivos de cada um dos níveis de base estudados e

- buscar traços evolutivos regionais para os sistemas fluviais da região.

\section{Localização e Vias de Acesso}

A bacia do rio Maracujá, com cerca de $150 \mathrm{~km}^{2}$, drena a porção centro-sul do Quadrilátero Ferrífero (a $\mathrm{S}$ de Belo Horizonte - MG), aproximadamente entre as coordenadas UTM E 630.090 - 641.630 e N 7.741.900 - 7.762.070.

As cabeceiras se encontram aproximadamente $15 \mathrm{~km}$ a SW de Ouro Preto. No médio curso, drena os distritos de Cachoeira do Campo e Amarantina. Sua foz se dá na confluência com o rio das Velhas, $750 \mathrm{~m}$ a montante da represa Rio de Pedras, cerca de $10 \mathrm{~km}$ a NE de Itabirito (figura 1).
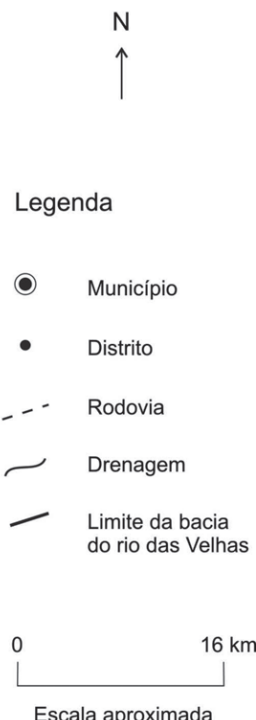

Figura 1 - Mapa de localização e vias de acesso à bacia do rio Maracujá. Modificado de Moura (2000). 


\section{Sinopse Geológica Regional}

A bacia do rio Maracujá conta com quatro unidades litoestratigráficas principais (Alkmim \& Marshak, 1998). São elas, da base para o topo: Complexo Bação (gnaisses e migmatitos arqueanos); Supergrupo Rio das Velhas (vulcânicas ultramáficas, máficas e félsicas intercaladas com rochas metassedimentares); Supergrupo Minas (quartzitos, metaconglomerados, metapelitos, itabiritos e mármores) e Intrusivas pós-Minas (diques máficos).

As principais estruturas da região são a sinclinal Dom Bosco, de eixo E-W, na extremidade $\mathrm{S}$ da bacia; e falhas de empurrão que limitam o Complexo Bação a E e SE, com vergência para W e NW (Lobato et al., 2005). Campos (2006) também relata a existência de famílias de fratura NW e NE que, ao serem alvos de reativação cenozóica, deformam sedimentos neogênicos no sudeste do Complexo Bação.

\section{Metodologia}

\section{- Identificação dos Níveis de Base}

As imagens SRTM (Shuttle Radar Topography Mission) são uma base de dados de uso crescente em geomorfologia, apresentando resolução espacial de $90 \mathrm{~m}$ e precisão vertical e horizontal de, respectivamente, 6,2 e $9 \mathrm{~m}$ (Grohmann et al., 2008). Isso motivou a sua adoção neste trabalho.

A partir da imagem SF-23-X-A, obtida no sítio da Empresa Brasileira de Pesquisa Agropecuária (Embrapa) (Miranda, 2005), foi gerado um modelo tridimensional de declividade via software ArcScene (pacote ArcView $9.2^{\circledR}$ ). Com base neste modelo identificaram-se 3 níveis de base.

Os pontos que se mostraram acessíveis para adensamento de estudos em cada um dos patamares definidos são apresentados na figura 2. Suas coordenadas UTM E e N são, respectivamente, 639.500 e $7.744 .640 ; 639.600$ e 7.746.830; e 637.230 e 7.751.300.
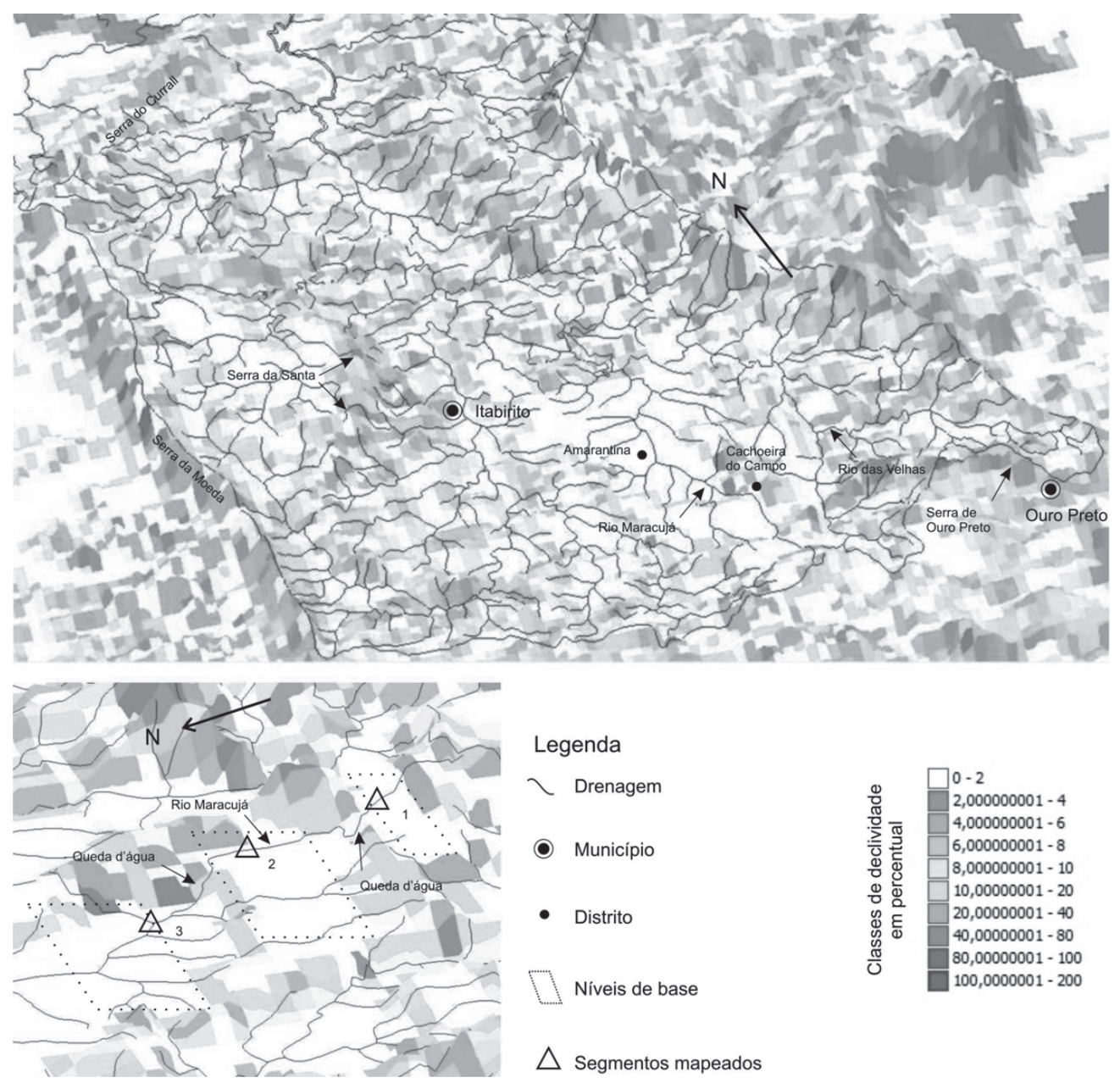

Figura 2 - Modelo tridimensional de declividade da área de trabalho gerado a partir de uma imagem SRTM. Exagero vertical de 5x. Destaque para a localização dos segmentos mapeados. Drenagem extraída de Moura (2000). 


\section{- Mapeamento e Levantamento de Perfis Estratigráficos}

Uma vez selecionados, os três segmentos foram mapeados com uma estação total Trimble ${ }^{\circledR}$ modelo 3305DR (precisão linear de $3 \mathrm{~mm}+/-2 \mathrm{ppm}$, precisão angular de 5 segundos e alcance de até $3.000 \mathrm{~m}$ ). Os métodos adotados foram o da "irradiação" e da "progressão" (Lahee, 1952). Optou-se por um espaçamento médio entre os pontos de $2,5 \mathrm{~m}$, resultando em mapas na escala 1:500.

O melhor pacote sedimentar exposto em cada segmento foi selecionado e posteriormente foram levantados os perfis de fácies em escala 1:10, conforme as técnicas estabelecidas em Compton (1985).

\section{- Interpretação de Mapas e Perfis}

Os mapas foram vetorizados no software $\mathrm{ArcGis}^{\circledR} 9.2$ e passaram por análises, juntamente com os perfis estratigráficos obtidos. Estes últimos foram digitalizados no
CorelDRAW $W^{\circledR} 4$ e posteriormente comparados com os modelos de fácies disponíveis em Walker (1984).

\section{Resultados Alcançados}

- Ponto 1: sinuoso, com um patamar úmido às margens, interpretado como planície de inundação. Acima deste nível, encontra-se um patamar de terraço aluvial restrito à margem esquerda (figura 3 ).

Em termos sedimentares, o ponto apresenta 3 barras cujas superfícies são ricas em seixos mal selecionados, subangulosos a subarredondados, de filito, quartzo e canga.

No perfil, levantado na planície de inundação (margem esquerda), foram identificadas as fácies: F1 - silte/argila intercalado a níveis de areia fina com laminações plano-paralelas e F2 - seixos finos subangulosos e mal selecionados de quartzo e, subordinadamente, rocha pelítica (figura 3).

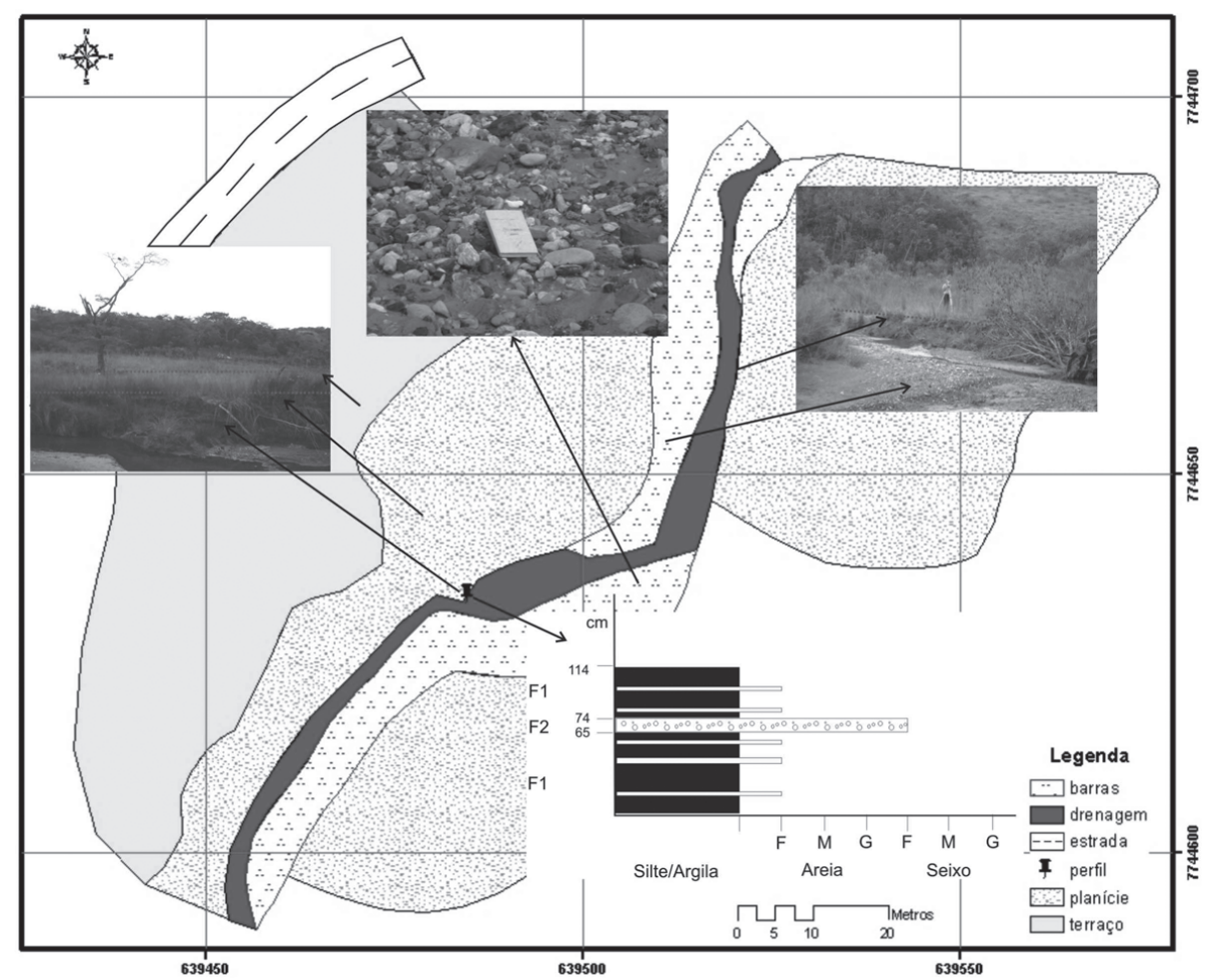

Figura 3 - Mapa geomorfológico do ponto 1, incluindo a representação do perfil descrito e fotos de feições observadas em campo.

- Ponto 2: possui uma faixa de planície de inundação na margem direita. A margem esquerda apresenta morfologia mais complexa, recebendo um afluente com planícies de inundação em ambas as margens (figura 4).

Ainda na margem esquerda existem três patamares interpretados como terraços aluviais. O mais alto deles, apresenta uma lagoa de cheia e dois segmentos de canais abandonados.
O canal principal possui 3 barras cuja superfície é marcada por seixos médios de quartzo, mal selecionados, variando de subarredondados a arredondados.

O perfil, descrito na margem esquerda do canal principal, apresenta na base um saprolito de gnaisse de 2,45 m sotoposto às seguintes fácies: F1 - seixos médios de quartzo subarredondados a arredondados, maciços e mal selecionados, com estratificação plano-paralela incipiente e ma- 
triz argilosa esbranquiçada; F2 - argila esbranquiçada maciça; F3 - argila esbranquiçada maciça com seixos esparsos de quartzo subarredondado; F4 - seixos de quartzo arre- dondados e bem selecionados e F5 - argila esbranquiçada, mosqueada em tons de vermelho, com matéria orgânica e raízes (figura 4 ).

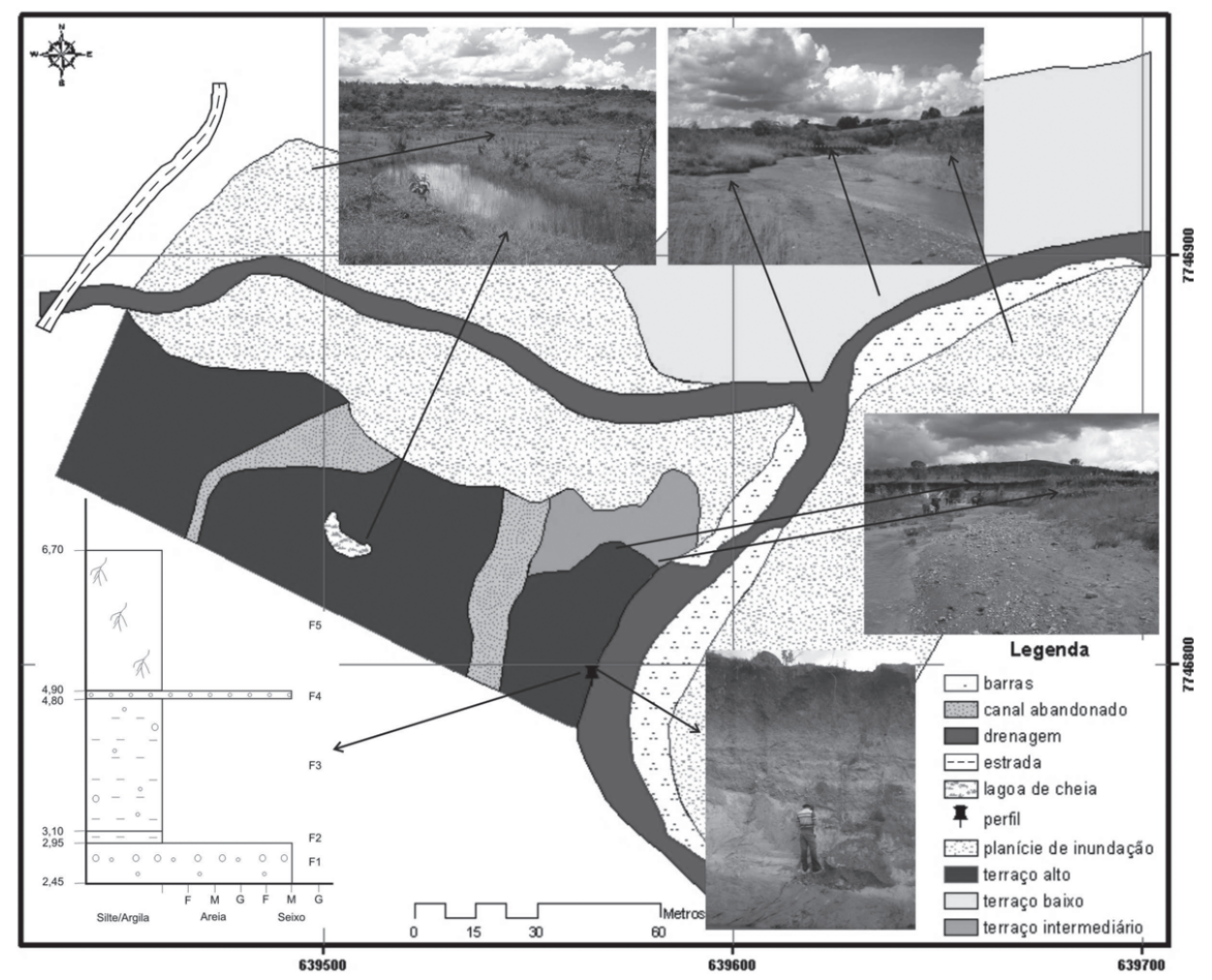

Figura 4 - Mapa geomorfológico do ponto 2, incluindo a representação esquemática e fotográfica do perfil descrito, além de fotos contemplando feições observadas em campo.

- Ponto 3: trata-se de um segmento com feições típicas de rios meandrantes. A margem direita é marcada por uma faixa descontínua da planície de inundação, limitada pelo terraço aluvial (figura 5).

A margem esquerda apresenta maior diversidade de formas. Além da planície de inundação e quatro resquícios de terraço aluvial, foram identificados dois segmentos fluviais abandonados e uma lagoa de cheia do tipo oxbow lake limitada por um depósito coluvial.

Em termos sedimentares, o rio apresenta conformação simples, com leito areno-argiloso a menos de dois metros da planície de inundação. Identificou-se apenas uma barra interna na porção mais a montante da margem esquerda, constituída de areia fina com alguns níveis de silte/argila.

Foi descrito um perfil de fácies de $70 \mathrm{~cm}$ na margem direita, onde foi identificada apenas uma fácie composta de areia média, bem selecionada, com grãos subarredondados de quartzo e laminações plano-paralelas. Estão presentes níveis intercalados de granulometria silte/argila ou areia fina escura.

\section{Discussões}

- Ponto 1: como pode ser observado na figura 6 , está a montante de uma zona de contato entre o embasamento arqueano da região (Complexo Bação) e as unidades supracrustais arqueanas e paleoproterozóicas: xistos do Grupo Nova Lima (Supergrupo Rio das Velhas); quartzitos do Grupo Caraça indiviso, dolomitos e itabiritos do Grupo Itabira e filitos do Grupo Piracicaba (Supergrupo Minas) (Lobato et al., 2005).

As supracrustais definem nesta área o flanco $\mathrm{N}$ da sinclinal Dom Bosco (de eixo aproximadamente E-W). Portanto, na zona de contato, marcada pela existência de uma cachoeira, os mergulhos são aproximadamente para S. Como o rio Maracujá drena para $\mathrm{N}$, tem de vencer não só a resistência de diferentes litotipos justapostos, mas também o efeito de seu mergulho em sentido contrário ao do curso d'água, se comportando como uma drenagem obsequente.

A predominância de fácies argilosas com intercalações de níveis de areia no perfil estratigráfico sugere acresção vertical em ambiente de planície de inundação meandrante. $\mathrm{O}$ 
nível cascalhoso deve estar associado a um depósito residual de corrente mais energética, durante um pulso de cheia. A constituição sedimentar atual de barras e leito indica um aumento na energia do sistema.

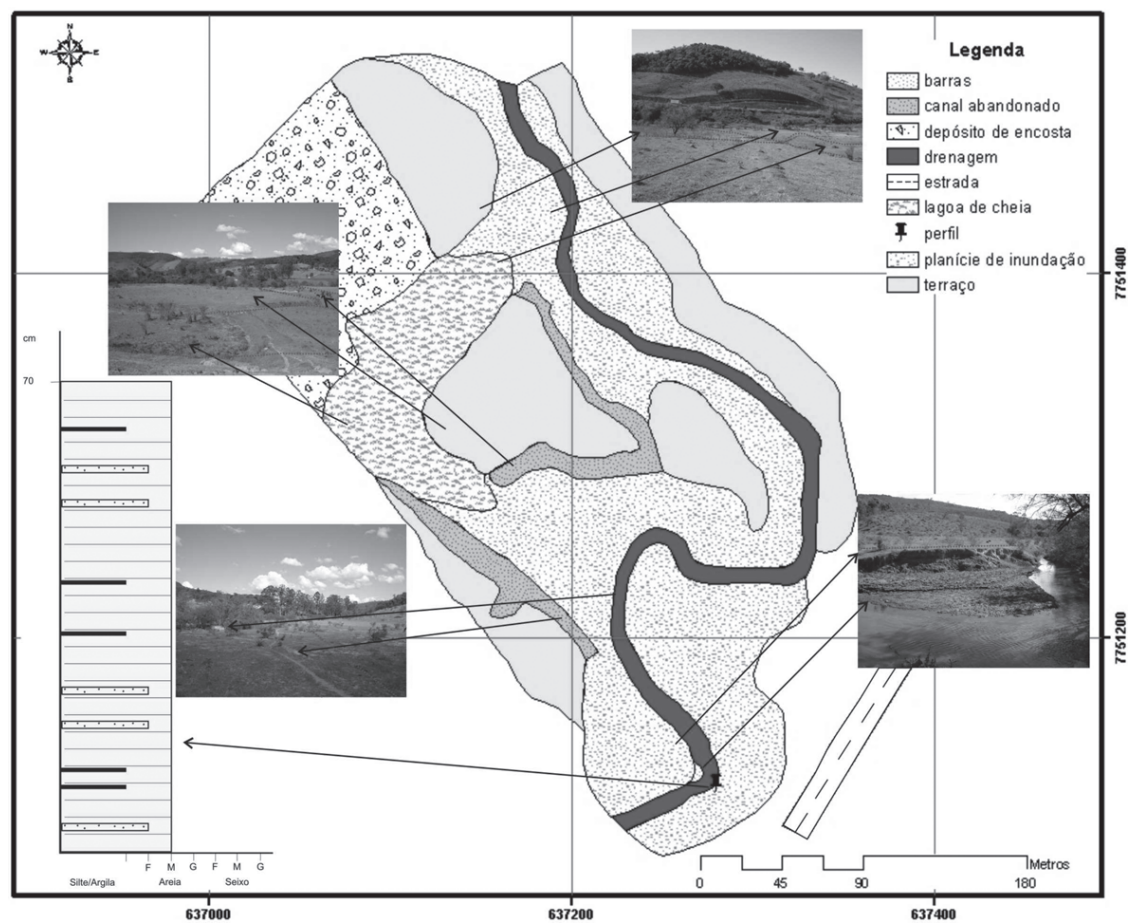

Figura 5 - Mapa geomorfológico e representação esquemática do perfil descrito no ponto 3, além de fotos contemplando feições observadas em campo.

Vale reforçar a assimetria do segmento, marcada pela maior riqueza de formas na margem esquerda, em contraposição à margem direita que, além de menor diversi- dade morfológica, está relativamente confinada junto a uma encosta íngreme.
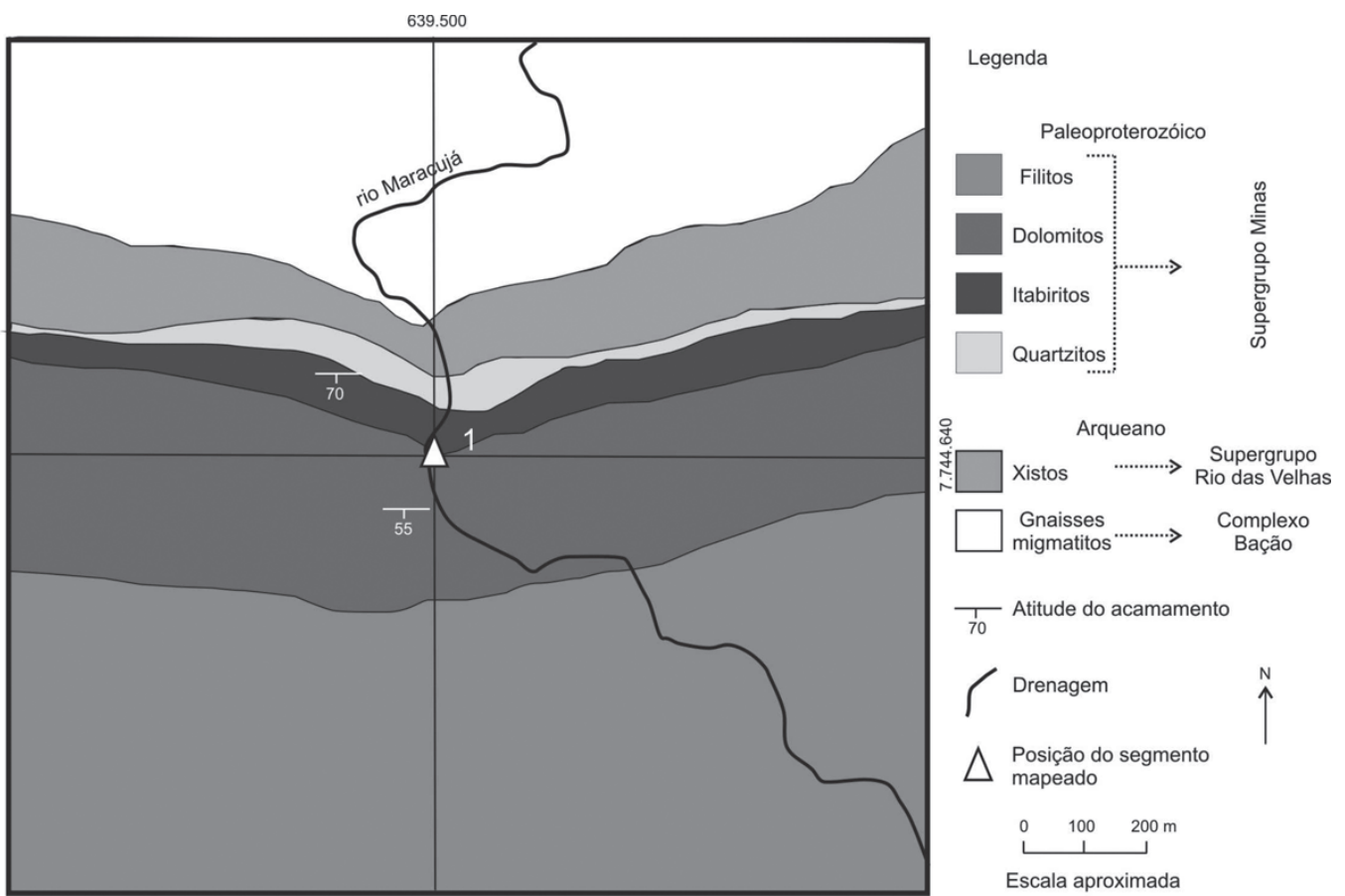

Figura 6 - Mapa geológico das imediações do ponto 1. Modificado de Lobato et al. (2005). 
- Ponto 2: localiza-se em uma zona de geologia mais homogênea, dominada pelas rochas metaígneas do Complexo Bação. Essas condições geológicas e o caráter agradacional se mantêm pelo curso d'água até a porção $\mathrm{N}$ de Cachoeira do Campo, onde ocorre a quebra do nível de base (Lobato et al., 2005).

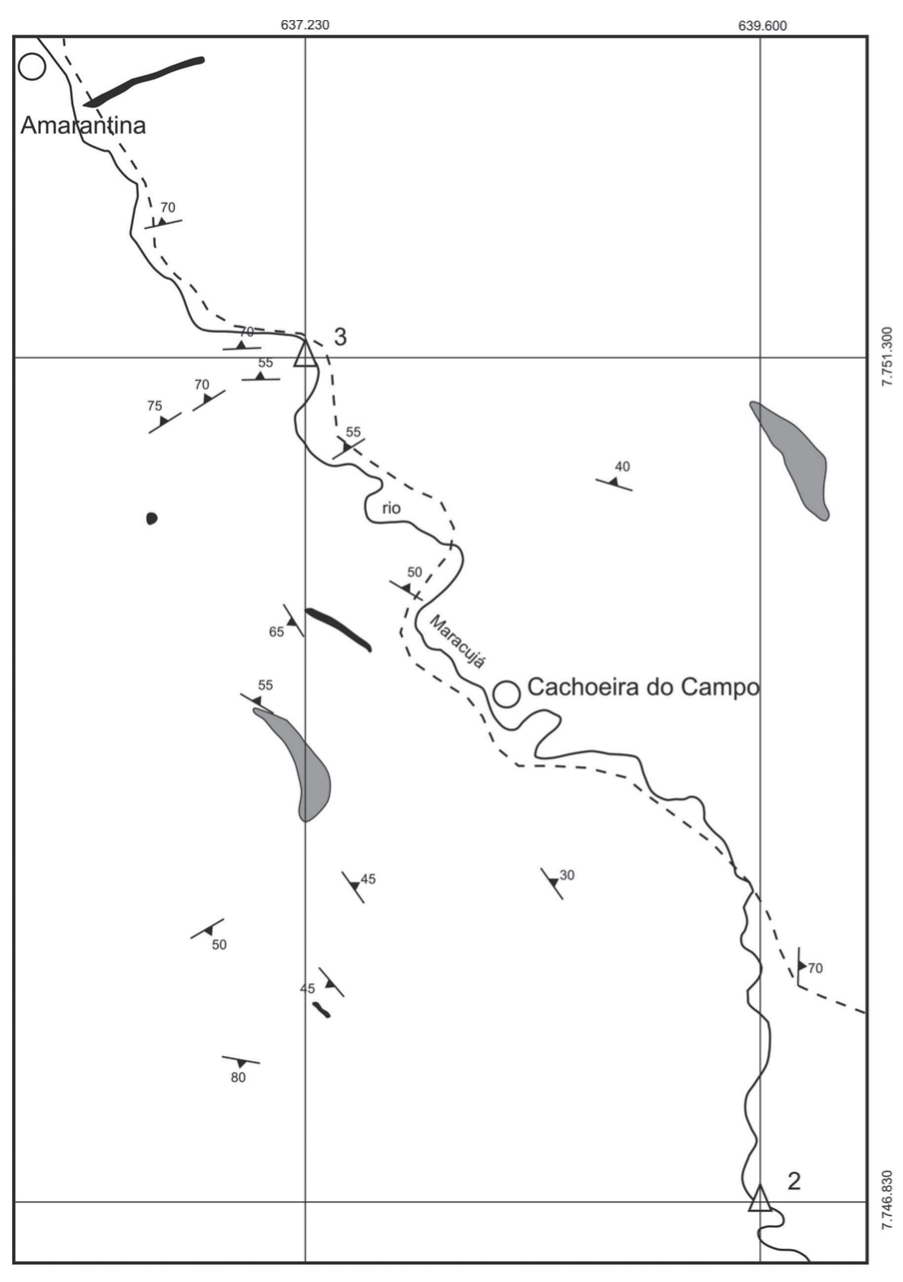

As fácies descritas sugerem um ambiente marcado por depósitos meandrantes residuais (lag deposits), frutos de retrabalhamento de barras e/ou outros depósitos residuais (F1 e F4). Alternadamente, ocorrem depósitos de acresção vertical em canal abandonado (F2 e F5), alguns contendo clastos esparsos, oriundos do retrabalhamento de depósitos pré-existentes (F3).

A morfologia é compatível com sistemas agradacionais. Tendo em vista o término abrupto dos canais abandonados no contato com a planície de inundação da margem esquerda, acredita-se que a mesma tenha sido gerada a partir de dissecação dos terraços e posterior preenchimento pelo canal tributário.
Na zona de quebra de nível de base, o rio apresenta-se encachoeirado, paralelo ao bandamento gnáissico e a um pequeno dique máfico de direção NW (figura 7). Antes de atingir o patamar mais baixo, a drenagem muda abruptamente de direção e verge para NE por cerca de 400 metros, voltando a drenar na direção NW.

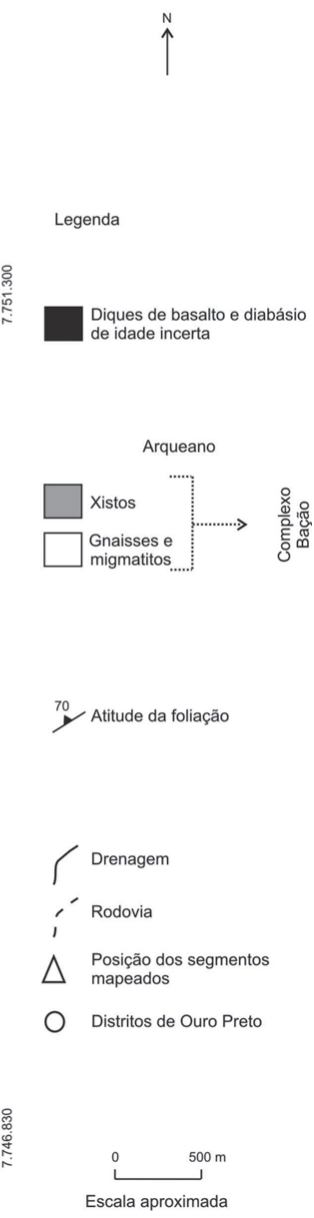

Figura 7 - Mapa geológico das imediações dos pontos 2 e 3 . Modificado de Lobato et al. (2005).

Para que tal dissecação ocorresse seria necessário que, após a fase agradacional, onde se geraria todo o pacote sedimentar descrito no perfil, houvesse o soerguimento da área ou o rebaixamento do nível de base. Essa posição é corroborada pela espessura exposta do pacote sedimentar, pela constituição sedimentar grossa do leito do canal principal e suas barras, além do próprio entalhamento do saprolito.

A assimetria das margens, marcada pelo desenvolvimento de várias feições escalonadas na margem esquerda, bem como pelo confinamento do canal junto à margem direita, merece ser citada.

- Ponto 3: drena o patamar mais baixo dentre os segmentos estudados e também se encontra instalado sobre as 
rochas do Complexo Bação. O caráter deposicional permanece até a foz do rio Maracujá. A aproximadamente $3,5 \mathrm{~km}$ a jusante do ponto mapeado, um dique máfico de direção NE (Lobato et al., 2005), concordante com o bandamento, aflora muito próximo à margem direita do rio que continua vergindo para NW (figura 7).

A morfologia observada está em concordância com os padrões clássicos estabelecidos para os rios meandrantes. $\mathrm{O}$ mesmo se aplica ao perfil levantado, onde a fácies descrita sugere acresção vertical.

A margem esquerda apresenta riqueza muito maior em termos de morfologia. Somado a isso, este segmento também apresenta uma notável assimetria de vale.

\section{Conclusões}

Os dados obtidos indicam que os três segmentos se desenvolveram de forma agradacional. Isto é compatível com a disposição topográfica em patamares da região em que estão instalados.

O ponto 1 está em um nível de base associado à justaposição litológica (figura 6). A perda de massa mais rápida dos terrenos granito-gnáissicos (Salgado, 2006) e o mergulho acentuado das rochas supracrustais (Lobato et al. 2005) permitem que as áreas dominadas por estas últimas permaneçam alçadas.

$\mathrm{O}$ ponto 2 tem suas características agradacionais associadas à presença de planos de fratura NW e NE que são paralelos ao bandamento gnáissico e sofrem truncamento a $\mathrm{N}$ de Cachoeira do Campo, condicionando abruptas inflexões da drenagem principal (figura 7). A reativação dessas estruturas na região SE do Quadrilátero Ferrífero, ao longo do Neógeno, foi constatada por Campos (2006).

A instalação de grabens de direção WNW na região data do Oligoceno ao Mioceno (Lipski, 2002). Já para o Plioceno, Saadi (1991) propõe a reativação de geossuturas a $\mathrm{N}$ do Quadrilátero Ferrífero.

A reativação neocenozóica de estruturas frágeis é sugerida pelas idades pleistocênicas e holocênicas, obtidas para alguns terraços do rio Maracujá por Bacellar (2000). O preenchimento da bacia do Gandarela a partir de reativação de falhas normais do Eoceno ao Eomioceno, advogado por Maizatto (2001), corrobora a idéia de continuidade temporal desses fenômenos.

A retenção de sedimentos no patamar do ponto 3 está relacionada à proximidade da confluência com o rio das Velhas. Porém, diques máficos perpendiculares ao fluxo aquoso, como aquele ilustrado na figura 7 , devem reforçar esta situação.
A constituição atual de leito e barras no ponto 1, somada ao entalhamento do canal, indica aumento na energia de fluxo devido à ruptura parcial das unidades metassedimentares próximo à zona de contato. Isto pode ser relacionado ao alcance de fraturas espaçadas ou porções de menor cimentação.

A dissecação de depósitos sedimentares e saprolito no ponto 2 são indícios de seu soerguimento em relação ao ponto 3. A reativação do knickpoint existente entre eles seria responsável pelo contraste entre a constituição sedimentar atualmente grossa do ponto 2 (leito e barras) e sua história estratigráfica e morfológica, que remetem a um sistema meandrante de menor energia. $\mathrm{O}$ referido contraste sugere que a reativação tectônica é um processo contínuo a jusante deste patamar.

Como a constituição de leito e barras do ponto 3 é mais fina que no ponto anterior, acredita-se que a reativação do knickpoint, impeça o intercâmbio efetivo de carga de fundo entre os dois pontos. Além disso, como o terraço cascalhoso está ausente no ponto 3 , infere-se que sua evolução remonte a um preenchimento mais recente, a partir de finos provenientes dos processos erosivos (ravinas e voçorocas) existentes a montante (Bacellar, 2000).

Conforme se pode perceber, todos os pontos mapeados são assimétricos e apresentam maior desenvolvimento morfológico em sua margem esquerda, ao passo que a direita se encontra confinada junto a áreas de maior declive.

Os fatos acima sugerem que os três patamares estejam sendo basculados em direção a $\mathrm{E}$, seguindo pulso pliocênico de reativação de geossuturas em resposta à migração da placa Sul-Americana para WNW (Saadi, 1991). Esta dinâmica seria continuada ao longo de todo o Cenozóico (Lipski, 2002, Campos, 2006, entre outros), tendo como plano regional de reativação a falha que limita o Complexo Bação a E e SE. Como a região se encontra bastante fraturada, é plausível que localmente o fenômeno se dê de forma escalonada e assíncrona ao longo dessa rede de descontinuidades, possibilitando a geração de calhas assimétricas, tais como os hemigrabens citados por Leeder \& Gawthorpe (1987).

Apesar de revolver um volume extra de sedimentos, o garimpo do topázio não parece ter um papel central no fenômeno de agradação, atuando junto aos processos erosivos de forma a potencializar o preenchimento de vales que naturalmente tenderiam a ser preenchidos. Análise semelhante pode ser feita em relação à retenção de fluxo pela ocupação das margens do rio Maracujá em Cachoeira do Campo. 


\section{Referências Bibliográficas}

ALKMIM, F. F.; MARSHAK, S. Transamazonian Orogeny in the Southern São Francisco Craton Region, Minas Gerais, Brazil: evidence for Paleoproterozoic collision and collapse in the Quadrilátero Ferrífero. Precambrian Research, Amsterdam, n. 90, p. 29-58, 1998.

BACELLAR, L. A. P. Condicionantes Geológicos, Geomorfológicos e Geotécnicos dos Mecanismos de Voçorocamento na Bacia do Rio Maracujá, Ouro Preto, MG. 2000. 226 f. Tese (Doutorado em Geologia) - Coordenação dos Programas de Pós-graduação em Engenharia, Universidade Federal do Rio de Janeiro, Rio de Janeiro, 2000.

CAMPOS, M. I. B. Caracterização da Deformação Frágil e sua Relação com os Processos de Voçorocamento na Porção Sudeste do Complexo Metamórfico Bação - Quadrilátero Ferrífero - Minas Gerais. 2006. 156 f. Dissertação (Mestrado em Geologia) - Departamento de Geologia, Universidade Federal de Ouro Preto, Ouro Preto, 2006.

CATUNEANU, O. Principles of Sequence Stratigraphy. Amsterdam: Elsevier, 2007. 375 p.

COMPTON, R. R. Geology in the Field. New York: John Wiley and Sons, 1985. 398 p.

GROHMANN, C. H.; RICCOMINI, C.; ALVES, F. M. Aplicações dos Modelos de Elevação SRTM em Geomorfologia. Revista Geográfica Acadêmica, Goiânia, n. 2, p. 73-83, 2008.

HOLBROOK, J. M.; SCHUMM, S. A. Geomorphic and Sedimentary Response of Rivers to Tectonic Deformation: A Brief Review and Critique of a Tool for Recognizing Subtle Epeirogenic Deformation in Modern and Ancient Settings. Tectonophysics, Amsterdam, n. 305, p. 287-306, 1999.

LAHEE, F. H. Field Geology. New York: McGraw-Hill Book Co., 1952. 883 p.

LEEDER, M. R.; GAWTHORPE, P. L. Sedimentary Models for Extensional Tilt-block / Half-graben Basins. In: COWARD, M. P.; DEWEY, J. E.; HANCOCK, P. L. (Eds.) Continental Extensional Tectonics. London: Geological Society of London Special Publications, n. 28, p. 139-152, 1987.

LIPSKI, M. Tectonismo Cenozóico no Quadrilátero Ferrífero, Minas Gerais. 2002. 171 f. Dissertação (Mestrado em Geologia) - Departamento de Geologia, Universidade Federal de Ouro Preto, Ouro Preto, 2002.
LOBATO, L. M.; BALTAZAR, O. F.; REIS, L. B.; ACHTSCHIN, A. B.; BAARS, F. J.; TIMBÓ, M. A.; BERNI, G. V.; MENDONÇA, B. R. V. de; FERREIRA, D. V. Projeto Geologia do Quadrilátero Ferrífero Integração e Correção Cartográfica em Sig. Belo Horizonte: Companhia de Desenvolvimento Econômico de Minas Gerais, 2005. Folha Ouro Preto. Escala 1:50.000.

MAIZATto, J. R. Análise Bioestratigráfica, Paleoecológica e Sedimentológica das Bacias Terciárias do Gandarela e Fonseca - Quadrilátero Ferrífero - Minas Gerais, com Base nos Aspectos Palinológicos e Sedimentares. 2001. 249 f. Tese (Doutorado em Geologia) - Departamento de Geologia, Universidade Federal de Ouro Preto, Ouro Preto, 2001.

MiALL, A. D. The Geology of Fluvial Deposits: Sedimentary Facies, Basin Analysis and Petroleum Geology. Berlin: Springer-Verlag Inc., 2006. 582 p.

MIRANDA, E. E. de (Coord.) Brasil em Relevo. Brasília: Embrapa Monitoramento por Satélite, 2005. Disponível em: http://www.embrapa.gov.br. Acesso em: 13 de maio de 2006.

MOURA, L. C. (Coord.) Desenvolvimento de Metodologia para Recuperação de Dados Cartográficos para Utilização em Base de Dados Georreferenciados. Belo Horizonte: Fundação Centro Tecnológico de Minas Gerais, 2000. Acompanham mapas de solos, geológico e geomorfológico, em escala $1: 250.000$.

NELSON, M. Hidrology and the River Environment. Oxford: Oxford University Press, 1998. 221 p.

SAADI, A. Ensaio sobre a Morfotectônica de Minas Gerais: Tensões Intra-Placa, Descontinuidades Crustais e Morfogênese. 1991. 285 f. Tese (Professor Titular) Instituto de Geociências, Universidade Federal de Minas Gerais, Belo Horizonte, 1991.

SALGADO, A. A. R. Estudo da Evolução do Relevo do Quadrilátero Ferrífero, MG - Brasil, Através da Quantificação dos Processos Erosivos e Denudacionais. 2006. $101 \mathrm{f}$. Tese (Doutorado em Geologia) - Departamento de Geologia, Unviersidade Federal de Ouro Preto, Ouro Preto, 2006.

SCHUMM, S. A. The Fluvial System. New York: John Wiley and Sons, 1977. 338 p.

SHANLEY, K. W. \& McCABE, P. J. Perspectives on Sequence Stratigraphy of Continental Strata. Am. Assoc. Petr. Geol. Bull., Tulsa, v.78, n. 4, p.544-568, 1994. 
TOOTH, S., BRANDT, D., HANCOX, P. J., MCCARTHY, T. S. Geological Controls on Alluvial River Behaviour: a Comparative Study of Three Rivers on the South African Highveld. Journal of African Earth Sciences, Amsterdam, n. 38, p. 79-97, 2004.

TURNER, T. R. \& LOCKE, W. W. River Terraces Below the 1959 Madison 'Slide. Department of Earth Sciences,
Montana State University, 2005. Disponível em: http:// www.homepage.montana.edu/ ueswl/madslide.html. Acesso em: 17 de julho de 2005.

WALKER, R. G. (Ed.) Facies Models. Hamilton: Geoscience Canada, 1984. 317 p. 